Rev. Biol. Neotrop. 4(1): 21-29. 2007

\title{
enologia e Biologia Reprodutiva de Tibouchina papyrus (Pohl) Toledo (melastomataceae) no Parque Estadual da Serra dos Pireneus, Goiás
}

\author{
Gustavo Ribeiro Montoro \\ Universidade de Brasília, Departamento de Botânica, Brasília, DF, Brasil, E-mail: gustavo- \\ cerrado@yahoo.com.br
}

\section{Mirley Luciene dos Santos}

Universidade Estadual de Goiás, Unidade Universitária de Ciências Exatas e Tecnológicas, Campus Henrique Santillo, BR 153, km 98, CEP 75001-970, CP 459, Anápolis-GO, Brasil. e-mail: mirley.santos@ueg.br

\begin{abstract}
Resumo: O estudo fenológico e reprodutivo de Tibouchina papyrus (Pohl) Toledo (Melastomataceae) foi desenvolvido em uma área de campo rupestre, a uma altitude de $1.100 \mathrm{~m}$ no Parque Estadual dos Pireneus, situado nos municípios de Pirenópolis e Cocalzinho-GO. Vinte indivíduos da população foram selecionados, marcados e acompanhados durante dois anos para observação dos eventos fenológicos de floração e frutificação. O sistema reprodutivo foi avaliado com polinizações manuais e cálculo da eficácia reprodutiva. Os frutos formados foram coletados e as sementes deles provenientes foram germinadas em placas de Petri sobre papel filtro umedecido. Os tratamentos de polinização manual indicaram a espécie como xenógama facultativa com maior formação de frutos por polinização cruzada (45\%) do que por autopolinização (12\%). Flores emasculadas para agamospermia não formaram frutos. A baixa formação de frutos-controle (30\%) pode ser explicada pela escassez de visitantes florais. A protusão da radícula ocorreu entre o 70 e o 80 dias com $55 \%$ de germinação. A floração estendeu-se de dezembro a junho, dependendo do ano, e o amadurecimento dos frutos, entre abril e outubro, coincidindo a dispersão das sementes com a queda foliar na estação seca. Este estudo forneceu subsídios para melhor entendimento do processo reprodutivo da $T$. papyrus, uma espécie endêmica e ainda pouco estudada.
\end{abstract}

Palavras-chave: Melastomataceae, pau-papel, campo rupestre, melitofilia.

Aвstract: The phenological and reproductive study of Tibouchina papyrus (Pohl) Toledo (Melastomataceae) was carried out in campo rupestre vegetation, at an altitude of $1,100 \mathrm{~m}$ in the Parque Estadual dos Pirineus, located in municipalities of Pirenópolis and Cocalzinho, in the state of Goiás. Twenty individuals of the population were selected, marked, and observed for two years regarding phenological processes such as flowering and fruiting. Their reproductive system was evaluated by manual pollination and calculations of reproductive efficacy. The fruits formed were collected and their seeds germinated in Petri dishes with wet filter paper. Treatments of manual pollination indicate this is a facultative xenogamy species with higher fruit production by cross-pollination (45\%) than by self-pollination (12\%). Emasculated flowers to induce agamospermy did not produce fruits. The low production of control-fruit $(30 \%)$ may be explained by low presence of pollinators. The protrusion of the radicle occurred between the $7^{\text {th }}$ and the $8^{\text {th }}$ day with $55 \%$ of germination. Flowering occurred from December to June, and fruit maturation between April and October, coinciding with seed dispersal and leaf fall during the dry season. This study provides information to understand the reproductive process of $T$. papyrus, an endemic and still not well studied species.

KEY woRDs: Melastomataceae, pau-papel, Campo rupestre, melittophily.

\section{INTRODUÇÃo}

A família Melastomataceae apresenta ampla distribuição nos trópicos, destacandose por sua grande diversidade de hábitos, o que permite a ocupação das mais diversas formações vegetais (Romero \& Martins, 2002). 
Apesar de sua ampla dispersão, ainda são poucas as informações sobre a ecologia da polinização e da biologia reprodutiva das Melastomataceae brasileiras, que somam mais de 1.500 espécies (Baumgratz \& Silva, 1986/88; Romero \& Martins, 2002).

Estudos com representantes das $\mathrm{Me}$ lastomataceae indicam que na família predominam espécies com sistema reprodutivo xenogâmico e melitófilas, i.e., nas quais ocorre polinização vibrátil por abelhas que se alimentam de pólen (Renner 1989; Goldenberg 1994; Santos 2003), embora tenham sido registradas espécies que apresentam apomixia, fenômeno pelo qual uma planta é capaz de produzir sementes com embriões viáveis sem que antes haja fusão de gametas e formação de zigoto (Goldenberg \& Shepherd, 1998; Goldenberg, 2000; Goldenberg \& Varassin, 2001).

Sendo assim, a investigação do sistema reprodutivo de Tibouchina papyrus (Pohl) Toledo, espécie com distribuição restrita ao estado de Goiás (Santos, 2003), contribuirá para o estudo mais amplo de caracterização do comportamento reprodutivo das espécies dessa importante família.

O objetivo deste trabalho foi obter dados sobre a fenologia e a biologia reprodutiva da $T$. papyrus em uma área de campo rupestre, uma vez que não existem na literatura informações sobre a reprodução dessa espécie.

\section{Material e métodos}

ÁREA DE ESTUdo

A presente pesquisa foi realizada em um dos pontos mais altos do Parque Estadual da Serra dos Pireneus, situado entre os paralelos $15^{\circ} 46^{\prime} \mathrm{S}$ e $15^{\circ} 50^{\prime} \mathrm{S}$ e longitudes $48^{\circ} 48^{\prime} \mathrm{W}$ a $48^{\circ} 53^{\prime} \mathrm{W}$, com área de aproximadamente 2.833,26 hectares. A Serra dos Pireneus separa geograficamente os municípios de Pirenópolis, Corumbá de Goiás e Cocalzinho, localizados no estado de Goiás. Trata-se de uma região com relevo acidentado, vegetação abundante, altitude média acima de 962 m e pluviosidade anual de aproximadamente $1.200 \mathrm{~mm}$, concentrada no período de outubro a abril (Oliveira et al., 2002). A temperatura média varia entre $21^{\circ} \mathrm{C}$ e $26^{\circ} \mathrm{C}$ ao longo do ano (Figura 1 ).

A população estudada de $T$. papyrus ocorre em uma área de campo rupestre, e os indivíduos selecionados encontram-se ao longo da estrada principal que corta o parque, a aproximadamente 20 km da cidade de Pirenópolis. Os indivíduos apresentam-se como arvoretas de 2-3 m de altura, com caule rosado e cujo ritidoma caracteristicamente esfolia-se em membranas papiráceas brancas.

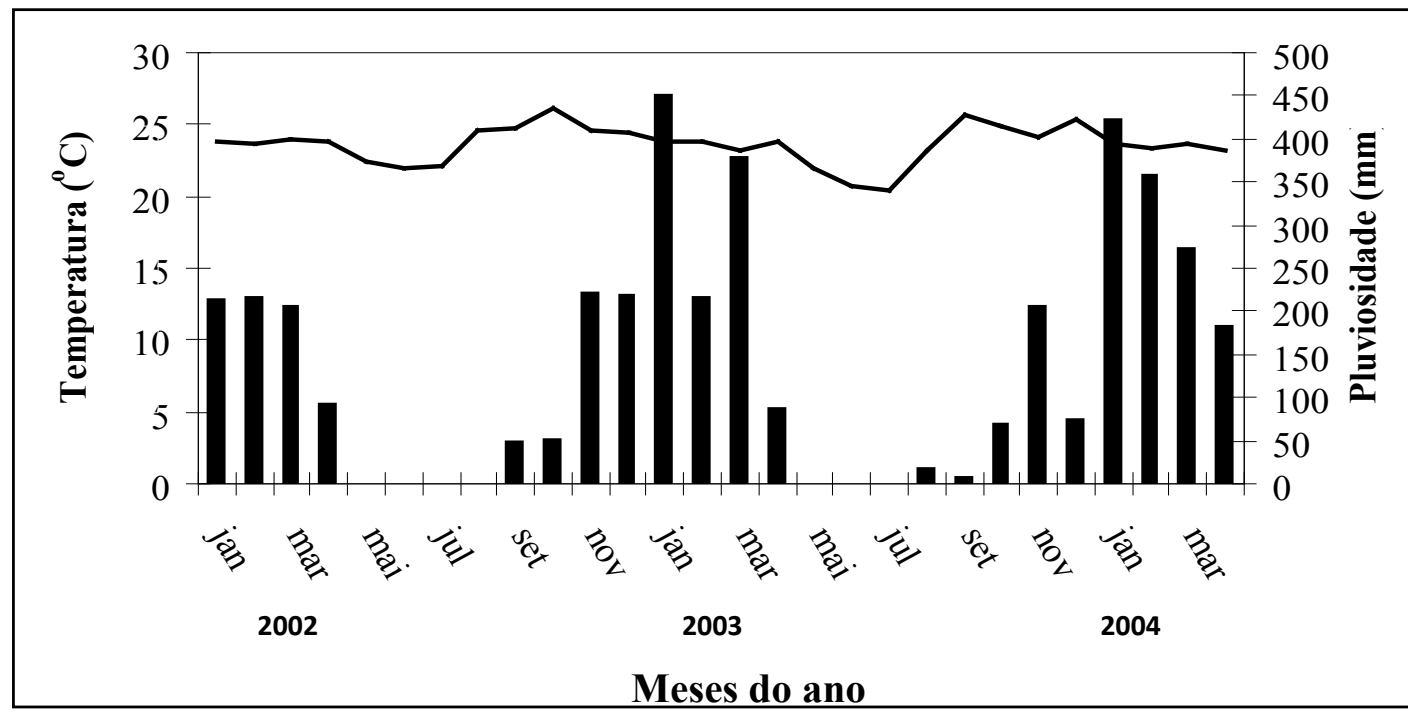

Figura 1 - Diagrama pluviométrico e de temperatura no município de Pirenópolis-GO, entre janeiro de 2002 e abril de 2004. Linha - Temperatura, Barras - Pluviosidade. (Fonte: INMET - GO). 


\section{Metodologia}

O estudo fenológico de Tibouchina papyrus foi realizado mensalmente entre os meses de janeiro de 2002 e abril de 2004. Vinte indivíduos da população foram selecionados ao acaso e marcados com chapas de alumínio e fitas vermelhas, sendo seu posicionamento geográfico registrado com o auxílio de Global Positioning System (GPS).

As fenofases observadas foram a floração e a frutificação. Para floração foram considerados botões florais e flores abertas, enquanto para frutificação foram considerados frutos imaturos e frutos maduros. A intensidade de cada evento foi estimada utilizando-se uma escala adaptada com base em Fournier (1974). Eventos como brotação foliar e caducifolia não foram quantificados, apenas registrados em seu período de ocorrência.

A morfologia floral foi observada a partir de material fresco ou fixado em álcool 70\%. Foram feitos desenhos com auxílio de microscópio estereoscópico e as medidas de comprimento e largura foram tomadas com paquímetro de precisão. Informações sobre horário da antese, duração da flor, presença de odor, tamanho e recursos florais também foram registradas.

Seis indivíduos foram selecionados e de cada um deles retirados cinco botões florais em pré-antese, os quais foram fixados em FAA $50 \%$ para testar a viabilidade dos grãos de pólen. Os grãos de pólen foram montados em lâmina, corados com carmim acético e observados ao microscópio óptico (Radford et al., 1974). Para cada lâmina foram contados os 100 primeiros grãos de pólen. A porcentagem de grãos viáveis foi calculada a partir da proporção entre grãos viáveis e não viáveis. Os grãos com citoplasma corado foram considerados viáveis e aqueles que não apresentaram citoplasma corado e morfologia regular foram considerados inviáveis (Goldenberg \& Varas$\sin , 2001)$.

Durante a floração, visitas adicionais foram feitas para que as polinizações manuais pudessem ser realizadas. Doze indivíduos foram selecionados e as flores receberam quatro tipos de tratamento: 1) polinização cruzada manual - as flores receberam pólen provenien- te de flores de outros indivíduos da mesma população; 2) autopolinização manual - as flores foram polinizadas com o próprio pólen; 3 ) apomixia - as flores tiveram as anteras e parte do estilete excisados na pré-antese; 4) polinização aberta (controle) - as flores foram apenas marcadas e deixadas ao acaso, sem tratamento posterior. Para a identificação dos tratamentos foram utilizadas linhas de cores diferentes. As inflorescências manipuladas foram protegidas antes dos tratamentos com sacos de organza de nylon e desensacadas apenas no momento da realização dos tratamentos para garantir flores não fecundadas. A razão entre a porcentagem de frutos resultantes de autopolinização manual e de polinização cruzada foi utilizada para definir o índice de auto-incompatibilidade (ISI sensu Bullock, 1985).

Os estiletes de flores tratadas foram fixados em FAA 50\% após intervalos de 24 h e 48 h. Para esses estiletes foram realizadas observações do crescimento dos tubos polínicos utilizando-se método adaptado de Martin (1959).

Os frutos formados foram coletados e as sementes deles provenientes foram colocadas para germinar. Primeiramente, foi realizada a assepsia das sementes utilizando-se solução de hipoclorito de sódio a $1 \%$ por $1 \mathrm{~min}$. Em seguida, as sementes foram lavadas em água destilada e colocadas para secar ao natural. Posteriormente, as sementes foram distribuídas em placas de Petri de $9 \mathrm{~cm}$ com dupla camada de papel filtro umedecido com água destilada $(5 \mathrm{~mL})$. Os frutos e as respectivas sementes foram separados de acordo com o tratamento reprodutivo que os originou: $T_{1}$ sementes originadas de autopolinização manual; $\mathrm{T}_{2}$ - sementes originadas de polinização cruzada manual; $\mathrm{T}_{3}$ - sementes originadas do controle. Os testes de germinação foram conduzidos em delineamento inteiramente casualizado, com 4 repetições de 25 sementes para cada tratamento. As observações foram feitas a cada dois dias a olho nu e ao microscópio estereoscópico e os resultados registrados durante 30 dias. Foram calculados a porcentagem de germinação e o tempo para início da germinação. As médias de germinação foram comparadas pelo Teste de Tukey a 5\% (Vieira \& Hoffmann, 1989). 
Os visitantes florais de T. papyrus foram observados regularmente durante o período de realização dos tratamentos florais no campo, contudo, sem ter sido feita sua quantificação. Para determinação desses visitantes florais, observou-se o comportamento e o horário das visitas e, com o auxílio de rede entomológica, alguns deles foram coletados, asfixiados em éter e fixados a seco para posterior identificação por especialista.

\section{Resultados}

A floração de Tibouchina papyrus ocorreu entre os meses de dezembro e junho, com pequena variação de um ano para outro. Os picos de floração foram registrados no final da estação chuvosa, entre os meses de março e abril (Figura 2A). A frutificação estendeu-se de fevereiro a outubro, ocorrendo o amadurecimento dos frutos durante a estação seca, entre os meses de abril e outubro (Figura 2B).

Observações não sistematizadas no campo evidenciaram que a caducifolia ocorreu entre os meses de maio e junho, permanecendo os indivíduos em repouso vegetativo até os meses de setembro e outubro, concomitantemente com a dispersão das sementes. A emissão dos primeiros brotos foliares ocorreu em seguida, mesmo antes das primeiras chuvas.

A inflorescência de Tibouchina papyrus caracteriza-se como panícula, com média de 15 a 20 botões florais. As flores, que apresentam atributos melitófilos, são actinomorfas e medem aproximadamente $1,5 \mathrm{~cm}$. A corola é violeta e dela partem 10 estames dimorfos, os quais apresentam filetes alongados e pilosos. As anteras são poricidas e o conectivo prolongado abaixo das tecas apresenta apêndice piloso (Figura 3). O ovário é adnato ao hipanto até a metade e apresenta 5 lóculos, com muitos óvulos por lóculo, o que gera grande quantidade de sementes.

Os valores encontrados para a viabilidade dos grãos de pólen estão apresentados na Tabela 1. A antese das flores de Tibouchina papyrus tem início por volta das 7h00 da manhã e a flor dura aproximadamente dois dias até sua completa senescência.
O estudo do sistema reprodutivo indica a espécie como xenógama facultativa. A emasculação não gerou frutos, determinando que a espécie não é apomítica (Tabela 2). O índice de auto-incompatibilidade (ISI) encontrado foi de 0,27 , o que revela que Tibouchina papyrus é autocompatível, embora esteja muito próxima do limite para espécies auto-incompatíveis (ISI $=0,25$ ). O resultado da análise do crescimento dos tubos polínicos evidenciou que tanto os tubos formados a partir de flores autopolinizadas quanto aqueles resultantes de polinizações cruzadas apresentaram comportamento semelhante e cresceram em grandes quantidades no estilete. Esses tubos foram observados na região da base do estilete e penetrando nos óvulos até $24 \mathrm{~h}$ após a polinização.

A germinação das sementes de T. papyrus ocorreu a partir do $7^{\circ} \mathrm{dia}$, estendendo-se até o $30^{\circ}$ dia, com taxa total de germinação de $60 \%$. A germinação das sementes resultantes de polinização cruzada foi maior em relação ao controle e à autopolinização (Tabela 3).

Abelhas das famílias Apidae, Anthophoridae e Megachilidae foram os principais visitantes observados nas flores de T. papyrus. Entre essas, foram coletadas espécies não identificadas de Centris (3 espécies), Xylocopa (1 espécie), Epicharis (1 espécie), Megachile (1 espécie) e Trigona (1 espécie). Foram observados indivíduos de Trigona sp. danificando botões e flores, assim como Polistes canadensis (L. 1758), espécie de vespa, promovendo a predação das partes florais. Xylocopa sp. foi a espécie mais freqüentemente observada em visita às flores de $T$. papyrus, apresentando-se como um de seus potenciais polinizadores. Durante as visitas, as abelhas dessa última espécie buscavam o pólen entre diferentes inflorescências e indivíduos. Essas visitas ocorriam por toda a manhã, até cerca de 12h30. Durante a visita, as abelhas exibiam movimento vibrátil diante da flor, fazendo com que o pólen fosse lançado ao ambiente. Parte do pólen retirado das flores de $T$. papyrus permanecia aderida aos pêlos que recobrem o corpo da abelha, assim entrando em contato com o estigma da flor e promovendo a polinização cruzada. 


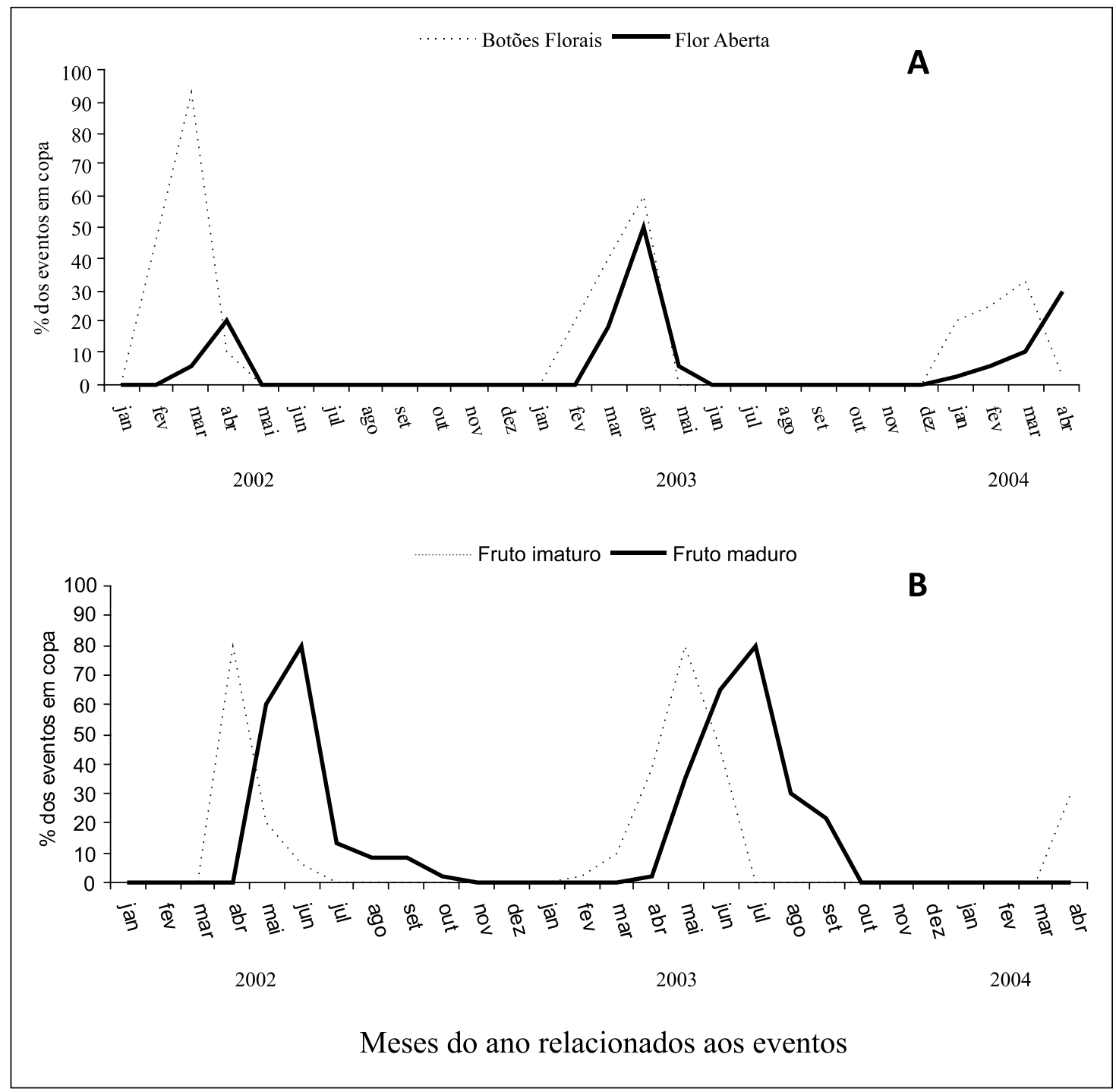

Figura 2 - Fenofases reprodutivas de Tibouchina papyrus (Pohl) Toledo (Melastomataceae), espécie estudada no Parque Estadual da Serra dos Pireneus, Estado de Goiás, no período de janeiro de 2002 a abril de 2004. Em A - ---Botões florais, —_Flor aberta; em B ---- Fruto imaturo, —— Fruto maduro.

Tabela 1 - Viabilidade dos grãos de pólen de Tibouchina papyrus (Pohl) Toledo (Melastomataceae) testada com carmim acético.

\begin{tabular}{|c|c|c|}
\hline Viabilidade polínica & Pólen (n) & Média (\%) \pm DP \\
\hline Grãos viáveis & 2.017 & $\mathbf{6 7 , 2 3} \pm 29,25$ \\
\hline Grãos inviáveis & 983 & $32,77 \pm 29,25$ \\
\hline Total & $\mathbf{3 . 0 0 0}$ & $\mathbf{1 0 0} \%$ \\
\hline
\end{tabular}

n - número de grãos de pólen;

DP - desvio-padrão da média. 


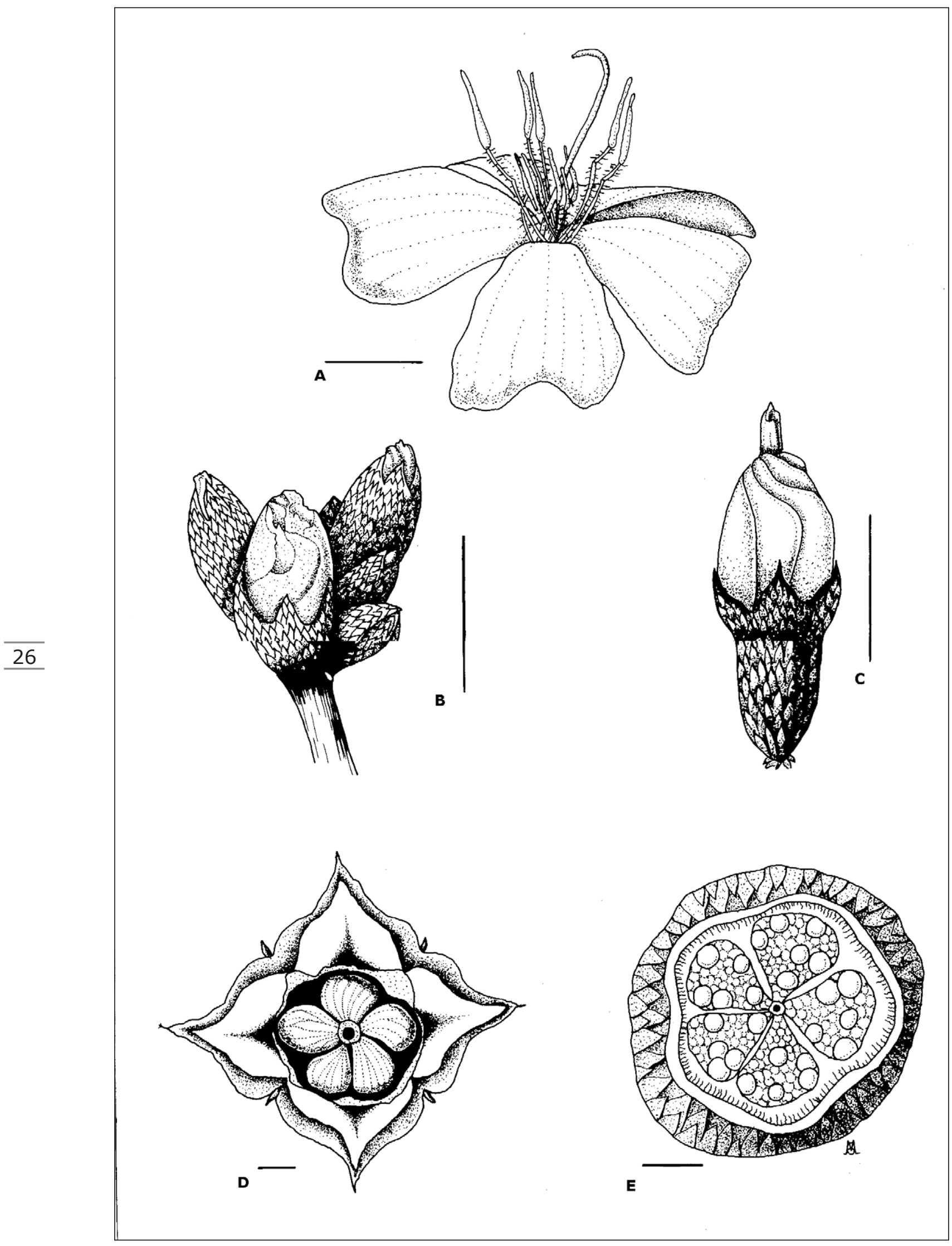

Figura 3 - Tibouchina papyrus (Pohl) Toledo.(Melastomataceae) (A) Aspecto geral da flor; (B) Inserção dos botões florais em uma inflorescência panícula; (C) Botão na pré-antese; (D) Vista superior do ovário pentalocular; (E) Corte transversal do ovário. Escala gráfica em (A), (B) e (C) corresponde a $1 \mathrm{~cm}$ e em (D) e (E), a $1 \mathrm{~mm}$. 
Tabela 2 - Polinizações manuais realizadas em flores de Tibouchina papyrus (Pohl) Toledo (Melastomataceae) no Parque Estadual da Serra dos Pireneus, Estado de Goiás, entre os meses de fevereiro e maio de 2002 e fevereiro e maio de 2003.

\begin{tabular}{|c|c|c|c|}
\hline Tratamento & Flor (n) & Fruto (n) & Sucesso reprodutivo (\%) \\
\hline Polinização cruzada manual & 151 & 68 & 45 \\
\hline Autopolinização manual & 94 & 11 & 12 \\
\hline Apomixia & 197 & 0 & 0 \\
\hline Controle & 259 & 78 & 30 \\
\hline
\end{tabular}

Tabela 3 - Porcentagem de germinação das sementes provenientes dos tratamentos reprodutivos realizados nas flores de Tibouchina papyrus (Pohl) Toledo (Melastomataceae) no Parque Estadual da Serra dos Pireneus, Estado de Goiás.

\begin{tabular}{|c|c|}
\hline Tratamento & Germinação (\%)* \\
\hline Cruzado & $82 \mathrm{a}$ \\
\hline Controle & $70 \mathrm{~b}$ \\
\hline Autopolinização & $28 \mathrm{c}$ \\
\hline
\end{tabular}

*Valores com letras diferentes diferem estatisticamente pelo teste de Tukey a 5\%.

\section{Discussão}

Tibouchina papyrus apresentou flores abertas por um período de quase cinco meses. Esse padrão de floração, com produção de flores por longo período de tempo na população e de forma assincrônica entre os indivíduos, é caracterizado como floração anual intermediária (Newstrom et al., 1993). Nas espécies com esse tipo de floração, as oportunidades para cruzamento não são tão limitadas pelo tempo, como observado naquelas em que há curto período de florescimento (Newstrom et al., 1993). Embora T. papyrus seja autocompatível, um padrão de floração que favoreça polinizações cruzadas será mais vantajoso para a espécie, que depende de vetores externos para o transporte de pólen (Santos, 2003). Assim, a pequena oferta de flores por unidade de tempo reduz o nível de geitonogamia e força os polinizadores a procurar alimento em outros indivíduos floridos dentro da população, aumentando as chances de cruzamento. $\mathrm{O}$ padrão de florescimento e o comportamento forrageador do polinizador devem estar influenciando diretamente a formação de frutos nessa espécie.
O período de amadurecimento dos frutos parece estar associado com a baixa precipitação pluviométrica, o que provavelmente ocorre pela necessidade que eles apresentam de se desidratar para liberar as sementes. Segundo Oliveira (1998), estratégias de frutificação de plantas têm sido relacionadas a mecanismos de dispersão, estando a anemocoria concentrada na estação seca. Ventos fortes, altas temperaturas e baixa umidade relativa do ar, característicos da estação seca, proporcionam o dessecamento e a deiscência dos frutos (Janzen, 1967), como observado nos frutos tipo cápsula de T. papyrus. A maturação antes do início das chuvas também favorece T. papyrus, pois suas sementes terão melhores condições para dispersão e germinação durante a estação chuvosa, que começa logo em seguida (Oliveira \& Gibbs, 1994; Santos, 1997; Oliveira, 1998).

Outro fator que favorece a dispersão das sementes de $T$. papyrus é a deciduidade observada na espécie. Durante os meses de estação seca ocorre a queda foliar total, permanecendo o indivíduo desprovido de copa até o final dessa estação, quando são emitidos 
os primeiros brotos foliares. Lieberman (1982) cita a existência de correlação significativa entre a emissão de folhas novas e a quantidade de chuvas precedendo a brotação.

Antese diurna e flores que apresentam apenas pólen como recurso caracterizam $T$. papyrus como uma espécie melitófila. Essa relação entre o vegetal e o polinizador garante a manutenção de ambas as espécies, uma vez que as abelhas recebem o alimento na forma de grãos de pólen e a espécie vegetal garante que haja a polinização na população.

Nas Melastomataceae, $98 \%$ das espécies oferecem apenas pólen como recurso para os polinizadores e a presença de anteras poricidas exige a polinização vibrátil (Buchmann, 1983).

De acordo com Buchmann (1983), o comportamento vibrátil exibido por alguns grupos de abelhas é muito rápido, porém é o bastante para que o inseto obtenha quantidade suficiente de pólen. Ao longo do dia, com a diminuição da quantidade de pólen nas anteras, as abelhas têm de visitar maior número de flores para obter a mesma quantidade de pólen coletada após a antese, nas primeiras horas da manhã. Esse comportamento resulta em altos níveis de transferência de pólen, o que é vantajoso para a espécie vegetal.

A grande porcentagem de grãos de pólen viáveis é mais um fator importante para a manutenção da população. Baixos índices de grãos de pólen viáveis representam baixa fecundação, ocasionando baixa produção de sementes (Borges, 2000).

A polinização cruzada manual foi o tratamento com maior sucesso reprodutivo nesta pesquisa, pois nela a troca de gametas ocorreu de forma orientada e forçada. Segundo Renner (1989), o sistema reprodutivo predominante da família Melastomataceae é o xenógamo, favorecido pela separação espacial entre o estigma e o pólen nas flores, o que explica a baixa formação de frutos a partir de autopolinização. Mesmo que haja a formação de frutos por meio de autopolinização manual em T. papyrus, a produção de frutos é superior sob condições naturais ou sob tratamento de polinização cruzada manual. Portanto, assume-se que a xenogamia facultativa ocorra nessa espécie. É comum entre as plantas a ocorrência de sistema reprodutivo misto, situação na qual espécies autocompatíveis também produzem sementes por intermédio de cruzamentos e a autofecundação aparece associada a diferentes níveis de fecundação cruzada (Waller, 1993).

Estudos feitos com a tribo Melastomeae indicam que, das 18 espécies estudadas, 72,2\% são autocompatíveis (Goldenberg \& Shepherd, 1998), assim como T. papyrus. Embora muitas espécies de Melastomataceae sejam autocompatíveis, necessitam de vetores de pólen para fazer a transferência (Gross, 1993). A existência de autocompatibilidade não necessariamente implica altos níveis de autogamia, o que parece ocorrer em T. papyrus, cuja porcentagem de frutos formados a partir de autopolinização foi de apenas $12 \%$ contra $45 \%$ de frutos formados por meio de polinizações cruzadas. A autogamia obrigatória é rara entre as Angiospermas (Goldenberg \& Varassin, 2001); assim, a menos que as abelhas vibrem sobre as flores, o pólen dificilmente será removido das anteras poricidas (Buchmann, 1983; Kearns \& Inouye, 1993).

Não foram formados frutos a partir da emasculação, evidenciando que $T$. papyrus não é uma espécie apomítica. Estudos realizados por Goldenberg \& Varassin (2001), na Serra do Japi (SP), indicaram que 7 entre as 13 espécies de Melastomataceae estudadas formam frutos a partir de apomixia. No entanto, entre as Melastomataceae, a apomixia ocorre com maior freqüência na tribo Miconieae, não sendo comum entre as Melastomeae, como exemplificado pelas espécies de Tibouchina já estudadas por Santos (2003).

Os dados resultantes dos experimentos de germinação de $T$. papyrus indicaram que as sementes provenientes de frutos formados a partir de polinização cruzada apresentaram maior índice de germinação (82\%), enquanto aquelas provenientes de frutos formados a partir de autopolinização apresentaram taxa germinativa de apenas $28 \%$. Esses dados corroboram o fato de que, mesmo em espécies autocompatíveis, os genótipos provenientes de polinizações cruzadas devem ser selecionados, o que aumenta a variabilidade genética da população e proporciona melhores condições de sobrevivência da espécie no ambiente.

Os polinizadores efetivos foram abelhas 
que exibiam comportamento vibrátil durante suas visitas às flores. A polinização vibrátil pode ser realizada por vários grupos de abelhas em guildas com especificidade apenas mediana (Buchmann, 1983). Em T. papyrus, o movimento vibrátil do polinizador pode promover tanto a polinização cruzada quanto a autopolinização, uma vez que a espécie é autocompatível.

Como a floração de T. papyrus é assincrônica, nem todos os indivíduos estão em plena floração simultaneamente, o que força o movimento dos polinizadores entre os vários indivíduos que estão afastados uns dos outros. Esse comportamento promove a polinização cruzada e, conseqüentemente, garante maior fluxo gênico. Dessa forma, durante os cinco meses (fevereiro a junho) em que $T$. papyrus apresenta flores abertas, espécies de abelhas visitam as flores à procura de pólen e promovem tanto a polinização cruzada quanto a autopolinização da espécie.

\section{Agradecimentos}

Os autores agradecem à Agência Ambiental de Goiás por ter permitido a realização do estudo na área do Parque Estadual dos Pireneus; à Universidade Estadual de Goiás pela concessão de Bolsa de Iniciação Científica (PBIC) durante parte do estudo; a Carolina Soares Pereira da Silva pela elaboração da prancha ilustrativa; ao Prof. Lúcio Campos, da Universidade Federal de Viçosa, pela identificação dos gêneros dos visitantes florais e ao Prof. Márcio da Silva Araújo, da Universidade Estadual de Goiás, pelo encaminhamento deles.

\section{ReferÊnCIAS}

Baumgratz, J. F. \& N. M. F. Silva. 1986/88. Ecologia da polinização e biologia da reprodução de Miconia stenostachya DC. (Melastomataceae). Rodriguesia, 64/66: 11-23.

Borges, H. B. N. 2000. Biologia reprodutiva e conservação do estrato lenhoso numa comunidade do Cerrado. Tese de Doutorado. Universidade Estadual de Campinas,
Campinas, SP.

Buchmann, S. L. N. 1983. Buzz pollination in Angiosperms, p. 73-113. In: C. E. Jones \& J. Little (Eds.) Handbook of experimental pollination biology. New York, Van Nostrand Reinhold.

Bullock, S. H. 1985. Breending system in the flora of a tropical deciduous forest in Mexico. Biotropica, 17: 287-301.

Fournier, L. A. 1974. Un método cuantitativo para la medición de características fenológicas em árboles. Turrialba, 24: 422-423.

Goldenberg, R. 1994. Estudos sobre a biologia reprodutiva de espécies de Melastomataceae de Cerrado em Itirapina, SP. Dissertação de Mestrado, Universidade Estadual de Campinas, Campinas, SP.

Goldenberg, R. 2000. Apomixia como alternativa à reprodução sexuada em Melastomataceae, p. 225-230. In: T. B. Cavalcanti, B. M. T. Walter (Eds): Tópicos atuais em botânica. Brasília, SBB/Embrapa Cenargen.

Goldenberg, R. \& G. J. Shepherd. 1998. Studies on the reproductive biology of Melastomataceae in "cerrado" vegetation. Pl. Syst. Evol. 211: 13-29.

Goldenberg, R. \& I. G. Varassin. 2001. Sistemas reprodutivos de espécies de Melastomataceae da Serra do Japi, Jundiaí, São Paulo, Brasil. Rev. Bras. Bot. 24: 283-288.

Gross, C.L. 1993. The breeding system and pollinators of Melastoma affine (Melastomataceae), a pioneer shrub in Tropical Australia. Biotropica, 25: 468-474.

Janzen, D. H. 1967. Synchronization of sexual reproduction of trees within the dry season in Central America. Evolution, 21: 620-637.

Kearns, C. A. \& D. W. Inouye. 1993. Techniques for pollinations biologists. Colorado, University Press of Colorado.

Lieberman, A. 1982. Seasonality and phenology in dry tropical forest in Ghana. J. Ecol. 70: 791-806.

Martin, F.N. 1959. Staining and observing pollen tubes in the style by means of fluorescence. Stain Tech., 34: 125-128.

Newstrom, L. E., G. W. Framkie, H. G. Baker \& R. K. Colwell. 1993. Diversity of longterm flowering patterns, p. 142-160. In: L. A. McDade, K. S. Bawa, G. S. Hartshorn, 
H. A. Hespenheide (Eds). La selva: ecology and natural history of lowland tropical rainforest. Chicago, University of Chicago Press.

Oliveira, P. E. 1998. Fenologia e Biologia reprodutiva das espécies de cerrado, p. 169-192. In: S. M. Sano, S. P. Almeida, (Eds). Cerrado: ambiente e flora. Planaltina: EMBRAPA-CPAC.

Oliveira, P. E. A. M. \& P. G. Gibbs. 1994. Pollinations biology and breeding systems of six Vochysia species (Vochysiaceae) in Central Brazil. J. Trop. Ecol. 10: 509-522.

Oliveira, A. A. M., D. D. Costa, D. P. Salgado, I. O. Moura, K. A. Teixeira, L. L. Santos \& S. M. M. Catein. 2002. Plano de gestão das unidades de conservação estaduais em Goiás - Proposta metodológica e executiva. Goiânia, Agência Ambiental de Goiás. (Documento do Departamento de Áreas Protegidas para a Gestão das Unidades de Conservação Estaduais.).

Radford, A. E., W.C. Dickson, J.R. Massey \& C.R. Bell. 1974. Vascular plant systematics. New York, Harper \& Row Publ, 891 p. biology in Neotropical Melastomataceae and Memecylaceae. Ann. Missouri Bot.

Gard. 76: 496-518.

Romero, R \& A. B, Martins. 2002. Melastomataceae do Parque Nacional da Serra da Canastra, Minas Gerais, Brasil. Rev. bras. Bot. 25: 19-24.

Santos, M. L. 1997. Biologia floral de duas espécies de Vochysiaceae em um Cerrado sobre afloramento basáltico em Araguari, MG. Dissertação de Mestrado. Universidade de Brasília, Brasília, DF.

Santos, M. L. 2003. Florística e biologia reprodutiva de espécies de Melastomataceae no Parque Estadual da Serra de Caldas Novas e Parque Estadual da Serra dos Pireneus, Goiás. Tese de Doutorado. Universidade de Brasília, Brasília, DF.

Vieira, S. \& R, Hoffmann. 1989. Estatística experimental. São Paulo, Editora Atlas, 190p.

Waller, D. M. 1993. The statics and dynamics of mating system evolution, p. 97-117. In: N.W. Thornhill (Ed.). The natural history of inbreeding and outbreeding. Theoretical and empirical perspectives. Chicago, University of Chicago Press.

Recebido em 21.V.2006 Aceito em 09.II.2007 